\title{
A espiritualidade no enfrentamento de crises globais
}

\section{Spirituality in global crisis's coping}

\author{
Espiritualidad ante las crisis mundiales
}

\section{Amanda Sales Cafezeiro ${ }^{*}$, Ana Lúcia Gonçalves de Oliveira Cunha ${ }^{2}$, Agnes Claudine De La Longuiniere ${ }^{3}$, Maria da Conceição Quirino dos Santos da Silva ${ }^{4}$, Alexandro Luiz Bomfim dos Santos ${ }^{5}$, Sérgio Donha Yarid ${ }^{6}$}

Como citar esse artigo. Cafezeiro, AS; Cunha, ALGO; De La Longuiniere, AC; da Silva, MCQS; dos Santos, ALB; Yarid, SD. A espiritualidade no enfrentamento de crises globais. Revista Pró-UniverSUS. 2020 Jul./Dez.; 11 (2): $168-173$.

\section{Resumo}

Introdução: Diversos estudos destacam a espiritualidade como mediador capaz de dotar os indivíduos de recursos importantes para a superação de adversidades. Considerando as periódicas crises enfrentadas pela humanidade ao longo da história, sejam resultantes de guerras, problemas econômicos, desastres ambientais ou doenças pandêmicas, e os impactos desestruturantes causados pelas mesmas, o objetivo deste artigo é refletir se a espiritualidade influencia o enfrentamento de crises globais, através da análise de eventos históricos. Materiais e Métodos: Trata-se de um estudo descritivo, tipo análise reflexiva, construída a partir de artigos científicos nacionais e internacionais pesquisados no Google Acadêmico, Lilacs, BVS, MEDLINE e na biblioteca SciELO. Resultados e Discussões: A pandemia do novo Coronavírus, evidenciou a necessidade de analisar o contexto das crises financeiras e acontecimentos globais trágicos ao longo de décadas, com ênfase ao processo vivenciado pela população mundial e as alternativas utilizadas no seu enfrentamento. Nessa perspectiva, considerou-se os relatos históricos e observou-se que a espiritualidade e a religiosidade estão associadas com a melhor saúde física e mental e com a maior eficácia na superação das crises. Considerações Finais: Ainda são escassas as pesquisas no campo da espiritualidade frente a calamidades, porém, ante a vivência de mais uma pandemia, há a necessidade de preenchimento dessa lacuna. Assim, verificou-se através de diversas ações humanas relatadas historicamente que a espiritualidade auxiliou de forma positiva no enfrentamento de crises e pandemias e pode ser aplicada como uma estratégia de manejo na atualidade.

Palavras-chave: Pandemias, Espiritualidade, Saúde Mental, Saúde Global, Economia e organizações de saúde, Prioridades em Saúde.

\begin{abstract}
Introduction: Several studies highlight spirituality as a mediator capable of providing individuals with important resources for overcoming adversity. Considering the periodic crises faced by humanity throughout history, whether resulting from wars, economic problems, environmental disasters or pandemic diseases, and the destructive impacts caused by them, the purpose of this article is to reflect on whether spirituality influences the coping with global crises, through the analysis of historical events. Materials \& Methods: This is a descriptive study, reflective analysis type, based on national and international scientific articles searched on Google Scholar, Lilacs, VHL, MEDLINE and the SciELO library. Results and Discussions: The new Coronavirus pandemic evidenced the need to analyze the context of financial crises and tragic global events over decades, with an emphasis on the process experienced by the world population and the alternatives used to cope with it. In this perspective, historical reports were considered and it was observed that spirituality and religiosity are associated with better physical and mental health and with greater efficiency in overcoming crises. Final Considerations: Research on spirituality in the face of calamities is still scarce, however, in the face of another pandemic, there is a need to fill this gap. Thus, it was verified through several human actions historically reported that spirituality helped in a positive way in coping crises and pandemics and can be applied as a management strategy nowadays.
\end{abstract}

Keywords: Pandemics, Spirituality, Mental Health, Global Health Economics and Organizations, Health Priorities.

${ }^{4}$ Enfermeira. Doutoranda em Enfermagem e Professora assistente da Universidade Estadual do Sudoeste da Bahia, Membro do Núcleo de Pesquisa em Bioética e Espiritualidade,

Departamento de Saúde II da Universidade Estadual do Sudoeste da Bahia (UESB), Jequié/BA, Brasil.

${ }^{5}$ Teólogo, granduando em psicologia, Universidade Estadual do Sudoeste da Bahia. Membro do Núcleo de Pesquisa em Bioética e Espiritualidade, Departamento de Saúde II da Universidade Estadual do Sudoeste da Bahia (UESB), Jequié/BA, Brasil.

${ }^{6}$ Cirurgião-dentista. Doutor em Odontologia Preventiva e Social pela UNESP. Professor Titular da Universidade Estadual do Sudoeste da Bahia (UESB). Coordenador do Núcleo de

Pesquisa em Bioética e Espiritualidade (UESB), Jequié/BA, Brasil .

* Email de correspondencia: amandacafezeiro@hotmail.com 


\section{Resumen}

Introducción: Varios estudios han destacado la espiritualidad como mediadora capaz de proporcionar a las personas recursos importantes para superar la adversidad. Teniendo en cuenta las crisis periódicas que enfrenta la humanidad a lo largo de la historia, ya sea como resultado de guerras, problemas económicos, desastres ambientales o enfermedades pandémicas, y los impactos destructivos causados por ellos, el propósito de este artículo es reflexionar sobre si la espiritualidad influye en el manejo de las crisis mundiales, a través del análisis de eventos históricos. Materiales y métodos: Análisis reflexiva, construido a partir de artículos científicos nacionales e internacionales investigados en Google Scholar, Lilacs, VHL, MEDLINE y la biblioteca SciELO. Resultados y Discusión: La nueva pandemia de coronavirus ha puesto de relieve la necesidad de analizar el contexto de las crisis financieras y los trágicos eventos mundiales a lo largo de décadas, con énfasis en el proceso experimentado por la población mundial y las alternativas utilizadas para enfrentarlo. En esta perspectiva, se consideraron informes históricos y se observó que la espiritualidad y la religiosidad están asociadas con una mejor salud física y mental y con una mayor efectividad para superar las crisis. Consideraciones finales: La investigación en el campo de la espiritualidad aún es escasa ante las calamidades, sin embargo, ante otra pandemia, es necesario llenar este vacío. Se verificó a través de varias acciones humanas que históricamente informaron que la espiritualidad ayudó positivamente a hacer frente a las crisis y pandemias y puede aplicarse como una estrategia de gestión hoy en día.

Palabras clave: Pandemias, Espiritualidad, Salud Mental, Salud Global, Organizaciones de Economía y Salud, Prioridades Sanitarias.

\section{Introdução}

Em diversos períodos, a humanidade enfrentou momentos recorrentes de crise, sejam resultantes de guerras, problemas econômicos, desastres ambientais ou doenças pandêmicas. Muitos destes eventos tiveram destaque na história, especialmente no século XX, dado aos seus caracteres de violência e destruição, que o definiram como o "século das catástrofes".

Atualmente, na era da informação, a população mundial é confrontada diariamente com anúncios de eventos trágicos: "o terrorismo internacional, o aquecimento global, as guerras internas e entre países, a violência cotidiana das grandes metrópoles, o tráfico internacional de drogas e de seres humanos" e, mais recentemente, uma pandemia de escala global ocasionada por uma infecção viral com alto poder de transmissibilidade, causadora de uma síndrome gripal que pode levar seu portador à óbito por insuficiência respiratória grave.

Dentro daquilo que se convencionou chamar de contemporaneidade, tem-se como signo de destaque a palavra crise, a qual, ainda que considerada sob amplo espectro, nos revela em sua essência mais profunda a crise de sentido, alterando profundamente o modo como o ser humano se coloca no mundo, seu projeto de vida para o futuro, bem como percebe e enfrenta seus desafios $^{3}$.

A palavra crise tem sua raiz etimológica no termo grego krisis, cujo sentido corresponde a "julgamento" ou "decisão", apontando para a necessidade de tomada de decisões em momentos emergenciais. Neste aspecto, a crise é uma situação crítica, envolvendo mudanças repentinas em determinado quadro, o que demanda tomadas de decisão e alteração de mecanismos internos para seu enfrentamento ${ }^{4}$. Este termo também tem sido usado em situações político-sociais, nas quais ocorrem mudanças repentinas de cenário, marcando um ponto de virada na situação atual ${ }^{5}$.
O que aqui se considera como ponto de virada, diz respeito a um antes e depois claramente demarcado pelos efeitos da crise nas pessoas, bem como no contexto em que vivem. Toda crise deixa $\operatorname{marcas}^{6}$, por tanto, convoca o indivíduo, bem como a sociedade a movimentos de ajustes.

Resiliência é um conceito tradicionalmente utilizado em referência ao potencial de superação de situações críticas, do qual alguns indivíduos são mais dotados do que outros, demonstrado a capacidade de tirar proveito das mesmas para crescimento pessoal. Estudos recentes demonstram que a espiritualidade pode ser um fator de favorecimento da resiliência, através da qual cenários desafiadores da vida podem passar a ser encarados por uma perspectiva de superação, culminando num alargamento do modo de perceber a realidade e estabelecendo novas formas de equilíbrio, logo, favorecendo o amadurecimento pessoal ${ }^{7}$.

O processo de resiliência possui vários fatores que o compõem e a espiritualidade se destaca como um mediador capaz de dotar o indivíduo de recursos importantes para a superação de adversidades. A espiritualidade é entendida como característica intrínseca do ser humano, que busca sentido e significado para a existência e considera fatores como o nível de conhecimento pessoal, o reconhecimento de uma verdade universal ou de um poder superior capaz de nos remeter a uma sensação de plenitude e bemestar com o mundo, de unidade com o cosmos e com a natureza. Assim, a espiritualidade tem sido apontada como aspecto do ser humano fundamental na resiliência, capaz de promovê-la e mediá-la ${ }^{8}$.

Seguindo esta perspectiva, o presente artigo pretende refletir se a espiritualidade influencia no enfrentamento de cenários de crise e acontecimentos globais trágicos. 


\section{Materiais e Métodos}

Trata-se de um estudo descritivo, tipo análise reflexiva, construída a partir de artigos científicos nacionais e internacionais pesquisados no Google Acadêmico, Lilacs, BVS, MEDLINE e na biblioteca SciELO. Os artigos foram analisados e agrupados por afinidade com as temáticas "espiritualidade", "crises mundiais" e "enfrentamento". O desenvolvimento da reflexão se deu a partir dos 25 artigos selecionados, abordando a questão da espiritualidade no enfrentamento das grandes crises mundiais.

\section{Resultados e Discussão}

\section{Espiritualidade e estratégias de enfrentamento}

Analisando o contexto das grandes crises mundiais como guerras, pandemias e crises financeiras, é possível constatar a capacidade que estas têm de alterar profundamente o modo de vida das populações. Das crises econômicas e militares, por exemplo, resultam não apenas impactos na economia, mas principalmente na saúde física e mental das pessoas, aumentando seus fatores de risco ao passo que os fatores protetores diminuem.

A correlação entre os prejuízos das atividades econômicas e a saúde coletiva, estão geralmente relacionados a diversos quadros como: o crescimento do índice de desemprego, da pobreza e da exclusão social, assim como à diminuição do investimento em serviços públicos de saúde e de proteção social por parte dos Estados, à mortalidade infantil e à mortalidade relacionada com homicídios e suicídios?.

Segundo dados da Organização Mundial de Saúde ${ }^{10}$ o estresse provocado por crises financeiras pode impactar diretamente a saúde mental das pessoas comprometendo as relações dentro do sistema familiar e aumentando a vulnerabilidade psíquica a problemas como depressão, ansiedade, uso abusivo de álcool e outras drogas e ao suicídio.

Asaúde mental, nesta perspectiva, está relacionada a certa competência pessoal para lidar com fatores estressantes, ou seja, que exigem flexibilidade cognitiva, afetiva e comportamental, tornando o indivíduo mais resiliente e adaptável às circunstâncias ${ }^{9}$.

A transição para o modelo paradigmático biopsicossocial da saúde, característico do século $\mathrm{XX}$, abre as portas para concepções mais holísticas acerca do ser humano, passando a compreendê-lo multifatorialmente. Assim sendo, estabeleceu-se terreno propício para que a espiritualidade pudesse ser concebida enquanto aspecto constituinte da subjetividade humana, logo atuante nos processos de saúde-doença.
A concepção de espiritualidade aqui utilizada não se refere às religiões ou aos dogmas $\mathrm{e}$, sim, a uma busca intrínseca do ser humano pela compreensão do sentido da vida, da transcendência, que pode incluir um sentimento de pertencimento para além do plano individual, envolvendo a contemplação e reflexão sobre as experiências da vida ${ }^{11}$.

O desenvolvimento da espiritualidade, ainda segundo Kóvacs ${ }^{11}$, é capaz de favorecer o acesso do sujeito a estados de transcendência, que elevam a compreensão dos acontecimentos da vida a partir de uma percepção mais ampliada. Este aspecto pode ser de extrema importância durante situações de crise da vida, pois auxilia o indivíduo a compreender o significado do sofrimento enfrentado nas perdas, separações e confrontos com a morte ${ }^{11}$.

No século passado, as guerras mundiais afetaram as sociedades de forma significativa, não somente em razão do número de mortos e destruição dos países, mas também pela forma como estes passaram a se relacionar. Entre 1914 a 1945, a sociedade mundial vivenciou duas guerras mundiais, diversas crises econômicas e pandemias, exigindo das pessoas alto grau de ressignificação das experiências enfrentadas de modo que as perdas não suplantassem o propósito da vida.

O eminente psiquiatra austríaco, Viktor Emil Frankl,nãoapenasexperimentou, masteveaoportunidade de observar em profundidade o comportamento humano diante das mais terríveis situações de calamidade e sofrimento, buscando identificar as razões pelas quais alguns prisioneiros conseguiram manter a esperança e lutar pela sobrevivência, quando durante a segunda Guerra Mundial, viveu em quatro campos de concentração nazistas.

Deste modo, Frankl desenvolveu toda sua obra apontando para a importância, ainda que em condições extremamente desfavoráveis, da busca pelo sentido da vida e sua potencialidade para a superação ${ }^{2}$. Ou seja, a crise pode ser um passaporte para a ressignificação da própria vida.

Corroborando com a temática, em seu trabalho, "Considerações sobre religião e saúde mental: uma compreensão psicodinâmica", Genaro tece considerações acerca do quanto essa busca pode tornar a pessoa mais resistente aos problemas. $\mathrm{O}$ autor descreve que em situações críticas, causadoras de grande aflição e agonia, a transcendência, uma visão para além do plano material, costuma ser mais frequentemente buscada ${ }^{12}$.

O sofrimento e as situações desafiadoras da vida, conforme pode ser percebido, podem ser estímulos à busca de sentido, e esta conferir ao indivíduo a possibilidade de elaborar os acontecimentos a partir de uma perspectiva mais ampla. Neste movimento, constatam-se importantes processos de mudanças nas vidas das pessoas, as quais, costumam relatar terem saído 
profundamente transformadas de grandes crises, como nos afirma: "quanto maior é o grau de paz e compreensão do que está ocorrendo, melhor é a tolerância à dor, capacidade de enfrentamento, resultando numa melhor qualidade de vida" 11

Uma outra vertente importante de estudo da espiritualidade é descrita a partir de suas dimensões afetivas e relacionais ${ }^{13}$. Enquanto emoções humanas positivas é o resultado de sentimentos conscientes, como: amor, respeito, aceitação esperança, compaixão, alegria, simpatia, perdão, fé, reverência e gratidão. Do ponto de vista relacional, estes sentimentos nos conectam aos outros seres humanos e ao divino de modo positivo, favorecendo atitudes mais colaborativas e altruístas.

Numa perspectiva cognitiva-comportamental, a espiritualidade é estudada em associação à religiosidade, tendo como foco os modelos de enfrentamento do estresse, ou seja, o coping religioso/espiritual ${ }^{14}$. Diante de eventos críticos, que ameacem a segurança e a vida das pessoas, a depender dos recursos pessoais de que estas disponham, é possível que percebam o contexto ambiental como além do que possam suportar, comprometendo seu bem-estar e gerando o estresse psicológico ${ }^{15}$.

O termo coping religioso/espiritual é definido como o uso da religião, espiritualidade ou fé para lidar com situações de estresse e as implicações negativas das dificuldades da vida, através de um conjunto de estratégias religiosas e/ou espirituais utilizadas para manejar o estresse diário e/ou advindo de crises existenciais ou circunstanciais ${ }^{16}$.

Impende ressaltar que as estratégias de coping religioso-espiritual podem, dependendo de sua natureza, ser positivas ou negativas, isto é, podem desenvolver e reforçar a resiliência ou constituir um problema maior no enfrentamento das adversidades. Assim, no coping religioso/espiritual negativo, a pessoa vivencia um ambiente social com normas rígidas, inflexíveis e condenatórias o que pode majorar o sofrimento psíquico e obstar os processos de resiliência ${ }^{17}$.

Insta salientar que em situações de desastre natural ou grandes crises comunitárias tem lugar a resiliência comunitária, definida como o atributo da coletividade "de ter capacidade esperança e fé para suportar a maioria dos traumas e perdas, superar a adversidade e prevalecer, geralmente com recursos, competência e união", e finalizam destacando o papel da família como a pedra fundamental de mudança ${ }^{18}$.

\section{Espiritualidade no enfrentamento de crises e acontecimentos globais trágicos}

Neste ínterim, necessário lembrar que após a Primeira Guerra Mundial o mundo vivenciou importante queda no padrão sanitário, ante a destruição experimentada no pós-guerra, e grande escassez de alimentos, propiciando o surgimento da Gripe Espanhola (Influenza Hespanhola). Até hoje considerada a pandemia mais devastadora e letal da história humana, propagou-se rapidamente por todo o mundo entre 1918 e 1920, atingiu pelo menos 600 milhões e vitimou entre 20 milhões e 50 milhões de pessoas ${ }^{19}$.

Não obstante a ausência de estudos relativos à espiritualidade como meio de enfrentamento da gripe espanhola ${ }^{19}$, em pesquisa sobre os efeitos da pandemia no Brasil, verificou que "a sociedade da época tomou para si a tarefa de minorar a crise vivenciada pelas camadas mais pobres da população" e que as doações de produtos, dinheiro e até atendimento médico gratuito eram divulgadas em jornais como atitudes louváveis que deveriam ser replicadas por aqueles que possuíssem condições, demonstrando o emprego da solidariedade, da interconexão positiva com os outros e da resiliência comunitária, como forma de amenizar os problemas ocasionados pela pandemia, que são aspectos da espiritualidade ${ }^{20}$

No dia 11 de setembro de 2001, os Estados Unidos foram alvo do mais elaborado ataque terrorista da história, em que aviões de carreira sequestrados por terroristas foram utilizados como bombas e destruíram as Torres Gêmeas do World Trade Center, em Nova York, atacaram o Pentágono, em Washington, e mataram 2.977 pessoas. Pela primeira vez, o mundo acompanhou uma ação terrorista ao vivo pela televisão, o que alterou significativamente a relação dos Estados ocidentais com a segurança ${ }^{21}$. Com o incremento das medidas de segurança, a restrição de direitos e as perdas humanas que sucederam os ataques, os americanos tiveram que se readaptar e desenvolver a resiliência necessária para superar o trauma ocasionado pelo ataque terrorista.

Cientistas investigaram o impacto do ataque às torres gêmeas nas comunidades do "baixo Manhattan" e os resultados demonstraram um aumento de $31 \%$ no abuso de drogas após a tragédia. $\mathrm{O}$ autor salientou que a adição é uma forma de adaptação negativa à desorganização pessoal, familiar e comunitária causada por catástrofes e que a reconexão da família e a proximidade desta com parentes, amigos e referências espirituais, bem como o rápido restabelecimento da rotina pessoal são extremamente importantes ${ }^{18}$.

Importante ressaltar que, em outro estudo, a religiosidade/espiritualidade representou uma das principais estratégias de enfrentamento utilizada pelos estadunidenses no enfrentamento do estresse causado pelos atentados, estando presente em $90 \%$ dos indivíduos entrevistados ${ }^{22}$.

O quadro mais recente de crise mundial, e que ainda se encontra em curso, teve início em um cenário pouco claro, em 31 de dezembro de 2019, quando a Organização Mundial da Saúde (OMS) alertou sobre vários casos, tidos até o aquele momento como 
pneumonia, na cidade de Wuhan, província de Hubei, na República Popular da China. Somente em 11 de março de 2020 foi declarada como uma Pandemia, já cientes de que se tratava do novo Corona vírus, que em pouco mais de três meses se tornou um grave problema de saúde mundial. O número de pessoas infectadas e vitimadas continua subindo exponencialmente, trazendo danos incalculáveis para a saúde da população e prejuízos para a economia mundial. Até o dia 30 de abril período de fechamento do presente trabalho, os números oficiais relataram 79.685 casos confirmados e 5.513 mortes apenas no Brasil e mais de 3.235.722 acometidos mundialmente, com 228.605 vítimas fatais ${ }^{23}$.

Diante de mais um provável colapso na saúde mundial, os indivíduos vêm demonstrando preocupação com o futuro, medo, ansiedade e outros sentimentos comuns em momentos de crise e totalmente válidos no momento atual. O pânico está em ascensão, já que não sabemos como e quando a pandemia terá seu desfecho, e mais ainda devido à necessidade de distanciamento/ isolamento social, suspensão das atividades ditas não essenciais e a quarentena obrigatória, que são as principais formas de prevenção.

Não obstante ainda ser cedo para avaliar o impacto que a pandemia do vírus Covid-19 causará a nível mundial, o futuro parece ser bastante desafiador, haja vista que alguns prejuízos já são notórios, como a expansão do contágio em todos os países, o aumento exponencial do número de infectados e mortos, a estagnação da economia mundial, a queda da bolsa de valore, desempregos em massa, entre outros.

Apesar da gravidade da pandemia do Covid-19, os estudos a respeito dos mecanismos de enfrentamento às grandes crises se encontram disponíveis, ainda que em pequena escala, demonstrando a importância do conhecimento já adquirido a partir das experiências anteriormente vividas, que podem funcionar como norteadores de novas pesquisas e direcionar intervenções técnicas no presente.

Nestas pesquisas, constata-se a importância da espiritualidade e dos valores a ela associados como a tolerância, esperança, compaixão, aceitação, fé, otimismo, alegria, empatia, perdão e gratidão. Estes, como já descrito, favorecem o apoio mútuo, possibilitando que a sociedade compartilhe suas necessidades, encontre estratégias próprias e desenvolva recursos de enfrentamento e resiliência.

De forma mais simples, é possível estimular a resiliência de uma comunidade, ou seja, sua capacidade de ter esperança e fé para suportar a maioria dos traumas e perdas, superar a adversidade e prevalecer, geralmente com recursos, competência e união ${ }^{18}$.

As pessoas possuem muitas competências e recursos que podem contribuir para a cura. Os membros da comunidade com diferentes experiências e idades contribuem de diferentes modos para a resiliência da comunidade. Os mais velhos trazem lembranças de lutas com tragédias anteriores, enquanto as crianças podem renovar a espontaneidade e a capacidade para brincar. As pessoas carregam uma diversidade de resistências e habilidades de acordo com a ocupação e os talentos - de artísticos a habilidades de administração organizacional, do sublime ao mundano. Esta recuperação deve ser um processo criativo, originando-se da sinergia de vários atores da comunidade, caminhando juntos para trabalhar em torno de um propósito comum ${ }^{24}$.

Conforme constatação, intervenções profissionais que auxiliem as comunidades em processos de superação precisam considerar, trabalhar e estimular as competências que as mesmas já possuem, favorecendo sua reorganização, empoderamento, fortalecimento de vínculos e elaboração de sentido para a experiência vivida, evitando separações hierárquicas que eventualmente possam colocar os profissionais em posições superiores de saber ${ }^{25}$.

\section{Considerações Finais}

Diante do cenário exposto, observou-se que as grandes crises globais enfrentadas pela humanidade, independentemente de suas origens, sejam guerras, problemas econômicos, sociais, culturais, desastres ambientais ou doenças pandêmicas, possuem efeitos sistêmicos na vida das pessoas, por alterarem as estruturas e padrões de modos de viver vigentes até então.

No âmbito coletivo, como pôde-se constatar, a espiritualidade é traço importante na construção da resiliência comunitária, favorecendo o apoio mútuo, possibilitando que a sociedade compartilhe suas necessidades, encontre estratégias próprias e desenvolva recursos de enfrentamento às crises.

Pode-se dizer, entretanto, que ainda são escassas as pesquisas no campo da espiritualidade diante de calamidades, principalmente as que analisam questões históricas. Todavia, ante a vivência de mais uma pandemia, há a necessidade de preenchimento dessa lacuna, e as pesquisas produzidas até então, apontam caminhos promissores. Conclui-se, assim, através de diversas ações humanas relatadas historicamente, que a espiritualidade auxiliou de forma positiva no enfrentamento de crises e pandemias, podendo, portanto, ser aplicada como uma estratégia de manejo na atualidade.

\section{Referências}

1. Hobsbawm E. Era dos extremos: o breve século XX: 1914-1991. Tradução de Marcos Santarrita. São Paulo: Companhia das Letras, 1994.

2. Trevisan AL \& Borin LC. A espiritualidade na formação de professores em tempos de catástrofes: considerações a partir de Viktor. CONJECTURA: filosofia e educação, 2018;23(Especial):78-95. 
3. Ribeiro FAS. Crise e emancipação no horizonte das espiritualidades não religiosas. Horizonte [Internet]. 2014 Out [citado 2020 Abr 20];12(35):654-7. Disponível em: http://periodicos.pucminas.br/ index.php/ horizonte/ article/view/P.2175-5841.2014v12n35p654.

4. Escorrega LF. 2010. Das novas Crises: Breves Contributos para a sua a sua classificação conceptual. Jornal de Defesa e Relações Internacionais. 2011 .

5. Lebow RN, Stein JG. Deterrence and the cold war. Political Science Quarterly, 10(2):157-81. DOI:10. 2307/ 2152358.

6. Seligmann SM, Nestrovski A. Catástrofe e Representação. São Paulo: Escuta, 2000, p 7-8.

7. Leal ALL et al. Resiliência e espiritualidade: algumas implicações para a formação humana. Conjectura: filosofia e educação [Internet]. 2010 Jan/Abr [citado 2020 Abr 17];15(1). Disponível em: http://www.ucs.br/etc/ revistas/index.php/conjectura/article/view/173/164.

8. Chequini MCM. A relevância da espiritualidade no processo de resiliência. Psicologia Revista, 2014 Fev.;16(1/2):93-117. ISSN 25943871. Disponível em: https://revistas.pucsp.br/psicorevista/article/ view/18059/13419. Acesso em: 2020 maio 06.

9. Antunes JAPJ. Economic crisis, health and disease. Psic.Saúde \& Doenças [Internet]. Psicologia, Saúde \& Doenças, Set 2015;16(2):267-77 [citado 2020 Abr 21];16(2):267-277. Disponível em: http://www.scielo.mec. pt/scielo.php?script $=$ sci arttext\&pid=S1645-00862015000200011\&lng=pt. http://dx.doi.org/10.15309/15psd160211.

10. Organização Mundial da Saúde (OMS). Relatório Mundial sobre a Deficiência (World Reporton Disability). The World Bank. Tradução: Secretaria dos Direitos da Pessoa com Deficiência do Governo do Estado de São Paulo, 2011. Disponível em: http://www.pessoacomdeficiencia.sp.gov. br/usr/share/documents/RELATORIO_MUNDIAL__ COMPLETO.pdf. Acesso em: 2020 mar 21

11. Kóvacs SMJ. Espiritualidade e psicologia - cuidados compartilhados. O Mundo da Saúde. [Internet]. O mundo da saúde, 2007 abr-jun;31(2):24655. [citado 2020 Abr 21];31(2):246-55. Disponível em: http://www. saocamilo-sp.br/pdf/mundo_saude/ 53/12_Espiritualidade.pdf

12. Genaro JRF. Considerações sobre religião e saúde mental: uma compreensão psicodinâmica. O Mundo da Saúde 2003;27(3):439-45.

13. Vaillant G. Fé: evidências científicas. Tradução Isabel Alves. Barueri, SP: Manole, 2010.

14. Panzini RG, Bandeira DR. Coping (enfrentamento) religioso/ espiritual. Rev. psiquiatr. clín. [Internet]. 2007 [cited 2020 Apr 21]; 34(Suppl1):126-135. Availablefrom: http://www.scielo.br/ scielo. php?script $=$ sci_ arttext\&pid=S0101-60832007000700016\&lng=en.https:// doi.org/ 10.1590/S0101-60832007000700016.

15. Lazarus RS, Folkman S. Stress, appraisal, andcoping. Springer Publishing Company, New York, 1984.

16. Pargament KI. The psychology of religion and coping: theory, research, practice. Guilford Press, New York, 1997, 548p.

17. Garcia DL, Sansonawicz TK, Nuernberg GL, Fleck MP, Rocha NS. Spirituality in psychiatric consultation: health benefits and ethical aspects. RevBras Psiquiatr. 2013;35:335-6.

18. Landau J, Saul J. Facilitando a Resiliência da Família e da Comunidade em Resposta a Grandes Desastres. Pensando Famílias, 2002;4(4):56-78.

19. Alves GW. Uma comparação entre a pandemia de Gripe Espanhola e a pandemia de Coronavírus. Disponível em: https://www.ufrgs.br/ifch/ index.php/br/uma-comparacao-entre-a-pandemia-de-gripe-espanhola-e-apandemia-de-coronavirus-por-gabrielle-werenicz-alves. Acesso em 20 abr 2020

20. Briggs MK, et al. "SpiritualityandtheeventsofSeptember 11: a preliminarystudy." CounselingandValues, vol. 48, no. 3, 2004, p. 174+. Acesso em 2020 abr 20

21. Araújo T. Memória: o 11 de setembro. Disponível em: https://super. abril.com.br/ história/memoria-o-11-de-setembro/. Acesso em 2020 abr 20.

22. Min JA, Jung YE, Kim DJ, Yim HW, Kim JJ, Kim TS, et al.
Characteristics associated with low resilience in patients with depression and/or anxiety disorders. Qual Life Res. 2013; 22: 231-41.

23. WHO. World Health Organization. Corona virus disease 2019 (COVID-19) Situation Report - 91. Disponível em: https://www.who.int/ docs/default-source/coronaviruse/situation-reports/20200420-sitrep-91covid-19.pdf?sfvrsn=fcf0670b_4. Acesso em 2020 abr 20.

24. Saul, J. Promoting Community Recovery in downtown Manhattan. BRIIFS: Bulletin of the Royal Institute for Interfaith Studies, 2004.

25. Souza MTS. Resiliência e desastres naturais. Cienc. Cult [Internet]. 2011. [cited 2020 Apr 22]; 63(3): 4-5. Available from: http:// cienciaecultura.bvs.br/scielo.php? script $=$ sci_arttext\&pid $=$ S0009 67252011000300002\&lng=en. $\quad$ http://dx.doi.org/10.21800/S000967252011000300002 . 